
\title{
Reseacch Soutere \\ Determinants of Under-five Child Mortality: Evidence from Bangladesh Multiple Indicator Cluster Survey (MICS) 2019
}

Md. Momin Islam ( $\sim$ momin@du.ac.bd)

University of Dhaka

Farha Musharrat Noor

University of Dhaka

Md. Rokibul Hasan

Bangladesh Bureau of Statistics

Mohammad Ahsan Udddin

University of Dhaka

Research Article

Keywords: Under-five child mortality, determinants, cox-proportional hazard model, Bangladesh

Posted Date: September 16th, 2021

DOI: https://doi.org/10.21203/rs.3.rs-855847/v1

License: (9) This work is licensed under a Creative Commons Attribution 4.0 International License.

Read Full License 


\section{Abstract}

Background: Every year millions of under-five children die due to different causes and some of those death could be prevented by proper awareness or taking steps. Though under-five child mortality rate has reduced by a remarkable rate for last decade in Bangladesh, the rate is still high to reach the expected level of Sustainable Development Goals (SDGs).

Methods: The main aim of this study was to find out the socioeconomic and demographic determinants of under-five child mortality in Bangladesh. Nationally representative cross-sectional secondary data from the Multiple Indicator Cluster Survey (MICS) 2019, Bangladesh had been used in this study. Outcome variable was under-five child survival status (alive or dead). Kaplan-Meier log-rank test and Cox Proportional Hazard (PH) model with 95\% confidence interval (Cl) were fitted to identify associated risk factors for under-five child mortality. This analysis was performed by using STATA version 16.

Results: The study showed that among 5112 under-five children, 170 (3.3\%) were dead. Cox proportional hazard model revealed that mother's education [secondary (HR: $0.53,95 \% \mathrm{Cl}:(0.30,0.94), p=0.03)$, higher (HR: $0.41,95 \% \mathrm{Cl}:(0.21,0.81), p=0.01)]$, higher birth order [HR: $1.43,95 \% \mathrm{Cl}:(1.13,1.89), p=0.007]$, size of child at birth [HR: $2.28,95 \% \mathrm{Cl}:(1.22,4.26), \mathrm{p}=0.009]$, taking antenatal care [HR: $0.77,95 \% \mathrm{Cl}:(0.52,1.15)$, $p=0.091]$ had a significant effect on child mortality. Under-five child mortality rate was varied among division and highest mortality rate was found in Sylhet [HR: 2.13, 95\% Cl: $(0.99,4.55), p=0.054]$.

Conclusions: This study identified potential risk factors for under-five child mortality, which would help the policy makers to take proper steps as community-based educational programs for mother's and public health interventions focused on birth to reduce under-five child mortality rate in Bangladesh.

\section{Background}

Under-five child mortality rate is the probability of dying a child before completing his/her fifth birthday. It is one of the important indicator for assessing the quality of a country's healthcare system. It is also the exponent of overall progression of a country, as it reflects the social, economic, and environmental conditions in which children live [1].

All over the world, 5.3 million children were died before completing their fifth birthday in 2018 [2]. Underfive child mortality rate is still highest in WHO African region (76 per 1000 live births) and lowest in WHO European region (9 per 1000 live births). Child mortality rate is high in low-income countries compared to high income countries. In low income countries, under-five child mortality rate was 68 per 1000 live births in 2018, which is almost 14 times the average rate in high income countries (5 per 1000 live births) [2]. Under-five child mortality rate has been decreased by $59 \%$ globally, from an estimated rate of 93 per 1000 live births in 1990 to 39 per 1000 live births in 2018 [2]. Half of all under-five deaths in 2018 occurred in just five countries: India, Nigeria, Pakistan, Ethiopia and the Democratic Republic of the Congo and about a third in India and Nigeria alone [3]. 
It is recognized that, under-five child mortality is a major challenge of a countries public health care system and included in Sustainable Development Goals (SDGs). Under goal 3 of SDGs aims to reduce under-five mortalities to 25 per 1000 live births by 2030 [4]. At present, under-five child mortality rate is more than 25 per 1000 live births in 79 countries of the world [3]. Leading causes of under-five deaths are diarrhea, malaria, preterm birth complications, pneumonia, birth asphyxia, congenital anomalies etc [3].

In developing countries like Bangladesh, under-five child mortality may be a major public health issue. In Bangladesh, child mortality rate was 30.2 deaths per 1000 live births in 2018 . A remarkable change of under-five child mortality rate has been experienced for few years, from 224.1 deaths to 30.2 deaths per 1000 live births in the period 1969-2018 [5]. In the meantime, Bangladesh has obtained the Millennium Development Goal-4 with 65\% decline rate between 1993 to 2014, but still now a large portion of children have been died due to lack of proper health care facilities and knowledge [6]. Despite the fact that child death rate is diminishing after some time, Bangladesh needs to additionally reduce child mortality to acquire the Sustainable Development Goals (SDGs) [7]. Different health care program such as immunization, control of diarrhoeal diseases, providing vitamin $A$ supplementation and implementation of family planning program are considered to be the most important factors to reduce child mortality, alongside potential impact of typical social and financial development.

From literature review, an evidence of association between child mortality and socio-economic characteristics of child's parents were found $[8,9,10]$. There are many determinants which are responsible for child mortality such as maternal education, economic status, health facilities, etc $[11,12$, $13,14]$. Different demographic variables are also considered for child death such as maternal age, maternal health complications, maternal BMI, type of birth, baby's size at birth, etc [11-14]. Media exposure may influence child mortality [15]. Birth interval less than 2 years have higher risk of child mortality compared to birth interval more than 2 years $[15,16,17]$. Birth order is also an important influential factor for child mortality. From many studies it was found that child mortality was comparably high for second birth order and more $[15,16]$. Many other factors such as mode of delivery, facility of pure drinking water, facility of improved toilet were responsible for child mortality $[16,17,18]$.

This study examined the socio economic and demographic factors which are responsible for child mortality and survival outcomes of children and siblings in Bangladesh. In developing countries, underfive child mortality data are collected from Demographic Health Survey which suggests that the lifetimes of children from the same cluster are correlated. This kind of correlation is frequently found at family level or community level which causes biased result due to violating the independence of event time assumption. In this situation, Cox-proportional hazards model is suitable because they allow for the correlation in survival expertise of children and their siblings and expected to calculate appropriate estimates of risk factors of child mortality.

Some studies had been done previously by considering the necessity of analyzing child mortality and its determinants in Bangladesh $[15,16,18]$. Although different interventional programs and policies had been taken by government and NGO's throughout the past few years, many of the health care sectors and 
social conditions have switched if the factors have interchanged over time. The aim of this study was to find out the socioeconomic and demographic factors provoking under-five child mortality in Bangladesh, which will help the policy makers and governments to find out the contention of child mortality for reducing the mortality rate by implementing necessary steps.

\section{Methods}

\section{Study population and variables}

Our study has been based on most recent Multiple Cluster Indicator Survey, 2019 data, which is nationally representative cross sectional study [19]. Information was collected from individual level (married women at their reproductive age) and community level. The survey was conducted in collaboration with Bangladesh Bureau of Statistics (BBS) and UNICEF Bangladesh from January to May 2019. A two-stage stratified cluster sampling method was used to select the sampling units and a total of 64400 households were enumerated. Among them, 3220 Primary Sampling Units (PSUs) were selected for sample survey. Data were collected from eight divisions and 64 districts in Bangladesh, on demographic or socio-economic characteristics such as marriage, fertility, maternal age, maternal education, child mortality, family planning, breastfeeding, information about HIV/AIDS, maternal health care etc.

In this study, data were collected from 23099 women at their reproductive age (15-49 years). Data on 9748 children aged below 5 years were generated from the interviewed women. Complete birth histories of the children were collected including months and years. These data were used to find out the number of children born in the last 5 years preceding the survey and child age at death (from 2014 to 2019). Among those information, 5112 children were considered for analysis due to incomplete interview or nonresponse (Figure 1). Those children who died before their fifth birthday were considered as death/uncensored cases and those who were still alive before their fifth birthday were considered as alive/censored cases.

The primary outcome variable of this study was child survival status classified as being alive (coded as 0 ) or dead (coded as 1). The primary potential modifiable risk factors were considered in this study include mothers age at first birth ( $<20$ years, $>=20$ years), mother's education (pre-primary or no education, primary, secondary and higher), area (urban, rural), division (Barisal, Chittagong, Dhaka, Khulna, Rajshahi, Rangpur, Sylhet), sex of child (boy, girl), babies size at birth (very large/average, very small), place of delivery (home, hospital/clinic), wealth index (poor, middle, rich), received antenatal care (ANC) during pregnancy (yes, no), caesarean delivery (yes, no), birth order $(1,2-3,4+)$, previous birth interval ( $1^{\text {st }}$ birth, $<2$ years, $<3$ years, +4 years), birth status (multiple birth, single birth), source of pure drinking water (pipe drinking water, non-pipe drinking water) and type of toilet facility (flush/ improved facility, none/non-improved facility

\section{Models}


Product-Limit (P-L) method: Product-Limit method proposed by Kaplan and Meir [20] is widely used in survival analysis for estimating the survival function and can deal with censored life time data. Suppose the event of interest occurs at $k$ distinct time points $\mathrm{t} 1<\mathrm{t} 2<\ldots<\mathrm{tj}<\ldots<\mathrm{tk}$. If $\mathrm{nj}$ and $\mathrm{dj}$ be the number of individuals at risk of failure and the number of individuals failed at time $t j ; j=1,2 \ldots, k$, respectively, then the Product- Limit estimate of the survival function $S(t)$ is given by

$$
\widehat{S(t)}=\prod_{j: \mathrm{t}<\mathrm{t}}\left(1-\frac{d j}{n j}\right)
$$

\section{Cox Proportional Hazard (PH) Model:}

In this study, the risk of death in childhood was measured in months and it was a time-to-event data. There exist distinguish possible survival model options and for this study an event history analysis procedure which was proposed by Cox [21]. It is usually used to examine the impact of various factors on the risk of death. Cox Proportional Hazard (PH) Model most commonly used for analyzing censored survival data where distribution of life time is considered as unknown or unspecified. According to Cox $\mathrm{PH}$, the hazard function can be defined as: $h(t \mid X)=h_{0}(t)^{\star} \exp \left(\beta^{\prime} X\right)$; where $h(t \mid X)$ is the hazard of child death at time $t, h_{0}(t)$ is the baseline hazard and $\beta=\left(\beta_{1}, \ldots, \beta_{m}, \ldots, \beta_{p}\right)^{\prime}$ being the $p^{\star} 1$ vector of regression coefficients associated with in presence of a set of covariates $X=\left(X_{1}, \ldots, X_{m}, \ldots, X_{p}\right)^{\prime}$.

\section{Statistical Analysis}

Descriptive statistics were used to summarize the distribution of selected background characteristics of under-five children. In this study, bivariate analyses were accomplished to find out the potential determinants of under-five child mortality. The prevalence of under-five child mortality according to the selected covariates was compared using Kaplan-Meier log-rank test [22] and the test has been employed to test whether the survival probabilities in different categories of a covariate are equal or not. Then with the significant factors (at $\mathrm{p}<0.05)$ from bivariate level, Cox $\mathrm{PH}$ model was fitted to assess the all possible risk factors for under-five child mortality. The results in adjusted cases were interpreted from the hazard ratios. STATA 16 employed to analyze the data.

\section{Results}

Descriptive Statistics: Out of the 5112 children below 5 years in the data set, 170 (3.3\%) of them were reported dead, 4942 (96.7\%) were alive (Fig. 1). The proportion of children belonging to urban area were $33.3 \%$. Among all children taken in this study, about two fifth (41.1\%) of the children lived in Chattogram and Dhaka division while boy and girl children proportion were almost same. Majority $2408(47.1 \%)$ of the children belonged to $2^{\text {nd }}-3^{\text {rd }}$ birth order and $91(1.8 \%)$ children were twins. About $4974(97.3 \%)$ were 
very large/average in size and 138 (2.7\%) were very small in size at the time of their birth respectively. The proportion of children belonging to women aged at first birth >=20 were 3586 (70.2\%). Majority of the children belonged to women with secondary education 2613 (51.1\%). A total of 2094 (41.0\%) of the children belonged to poor wealth index while 966 (18.9\%) belonged to rich wealth index. About $84.3 \%$ of children belonged to women who were taking any form of antenatal care during her pregnancy and $57.1 \%$ of women gave birth her child at hospital/clinic. A total of 1995 (39.0\%) children belonged to women who delivered through caesarean section. It was found that, in total, $4667(91.3 \%)$ children belonged to household with non-piped source of drinking water while 2682 (52.5\%) of them belonged to households without toilet/none improved facilities.

Bivariate Analysis: Product-Limit (P-L) approach had been used for bivariate analysis to estimate the survival probabilities. Log-Rank test had also been employed to test whether the survival probabilities in different categories of a covariate were equal or not. Fig. 2 exhibited the graphical presentation of the survival curves for the selected covariates obtained from P-L method along with Log-rank test p-values. The variables that had been found having significant association with under-five mortality at $5 \%$ level of significance were area, division, birth order, size of child at birth, mother's education level, wealth index, received antennal care, caesarean delivery, source of drinking water, type of toilet facility and these variables were considered in the regression analysis.

Semi-parametric survival regression analysis: From Table 1, the estimated hazard ratios had been obtained using Cox PH model along with 95\% confidence interval and corresponding p-values to test whether the variables had significant effect on under-five mortality or not. It was clear from Table 1 that the children whose mothers live in Chattogram, Mymenshing and Sylhet have $(1.91-1) \star 100 \%=91 \%$ higher, $(2.12-1) * 100 \%=112 \%$ higher and $(2.13-1) * 100 \%=113 \%$ higher rate of under-five mortality, respectively compared to the children who belong to Barisal division and these results had been found significant at $10 \%$ level of significance.

\section{Table 1}

\section{Cox's proportional hazards model analysis: determinants of under-five child mortality in Bangladesh using the data set MICS 2019.}




\begin{tabular}{|c|c|c|}
\hline \multirow[t]{2}{*}{ Characteristics } & \multirow[t]{2}{*}{ Hazards Ratio (HR) $(95 \% \mathrm{Cl})$} & \multirow[b]{2}{*}{ P-value } \\
\hline & & \\
\hline \multicolumn{3}{|l|}{ Area } \\
\hline Urban & 1 & \\
\hline Rural & $1.31(0.81,2.14)$ & 0.269 \\
\hline \multicolumn{3}{|l|}{ Division } \\
\hline Barisal & 1 & \\
\hline Chattogram & $1.91(0.95,3.83)$ & 0.068 \\
\hline Dhaka & $1.36(0.64,2.86)$ & 0.420 \\
\hline Khulna & $1.11(0.49,2.53)$ & 0.794 \\
\hline Mymenshing & $2.12(0.95,4.72)$ & 0.067 \\
\hline Rajshahi & $1.55(0.70,3.42)$ & 0.280 \\
\hline Rangpur & $1.65(0.76,3.55)$ & 0.205 \\
\hline Sylhet & $2.13(0.99,4.55)$ & 0.054 \\
\hline \multicolumn{3}{|l|}{ Birth Order } \\
\hline First birth & 1 & \\
\hline $2^{\text {nd }}-3^{\text {rd }}$ & $0.77(0.57,1.06)$ & 0.111 \\
\hline $4+$ & $1.43(1.13,1.89)$ & 0.007 \\
\hline \multicolumn{3}{|l|}{ Size of child at birth } \\
\hline Very large/ Average & 1 & \\
\hline Very small & $2.28(1.22,4.26)$ & 0.009 \\
\hline \multicolumn{3}{|l|}{ Mother's education level } \\
\hline Preprimary or No education & 1 & \\
\hline Primary & $0.68(0.38,1.23)$ & 0.208 \\
\hline Secondary & $0.53(0.30,0.94)$ & 0.030 \\
\hline Higher Secondary & $0.41(0.21,0.81)$ & 0.010 \\
\hline \multicolumn{3}{|l|}{ Wealth index } \\
\hline Poor & 1 & \\
\hline Middle & $1.26(0.86,1.84)$ & 0.236 \\
\hline
\end{tabular}




\begin{tabular}{|lll|}
\hline Rich & $0.73(0.36,1.50)$ & 0.398 \\
\hline No & 1 & \\
Yes & $0.77(0.52,1.15)$ & 0.091 \\
\hline Place of delivery & & \\
\hline Home & 1 & 0.919 \\
Hospital/Clinic & $0.98(0.70,1.38)$ & \\
\hline Source of drinking water & & \\
\hline Non-piped drinking water & 1 & 0.472 \\
Pipe drinking water & $0.75(0.35,1.62)$ & \\
\hline Type of toilet facility & & 0.353 \\
\hline $\begin{array}{l}\text { None/Non-improved } \\
\text { Flush/ Improved facility }\end{array}$ & 1 & \\
\hline
\end{tabular}

It has been observed that higher birth order children mortality rate was significantly $(1.43-1) * 100 \%=43 \%$ higher (as p-value $=0.007$ ) compared to the lower birth order children. Size of child at birth plays an important role to determine under-five child mortality. Very small size children had significantly (2.28$1) \star 100 \%=128 \%$ higher rate of under-five mortality compared to the very large/average in size children at the time of their birth. Also, children of secondary and higher educated mother had $(1-0.53) * 100 \%=47 \%$ lower rate and $(1-0.41) * 100 \%=59 \%$ lower rate of mortality compared to the children of illiterate mothers at $5 \%$ and $1 \%$ level of significance, respectively. Children belonged to the mother who received antenatal care during her pregnancies have significantly $(1-0.77) * 100 \%=23 \%$ lower rate of mortality than whose mother did not received any kinds of antenatal care.

\section{Discussion}

The study had been set up to develop predictive model to identify modifiable risk factors for under-five mortality in Bangladesh. This study observed that under-five child mortality rate was 33.3 per 1000 live birth in Bangladesh. The rates of under-five child mortality have been decline over last few years, which indicates the improvement of the quality of health sectors of the country. Among South Asian countries, under-five child mortality rate was found lowest in Sri Lanka with 9 deaths per 1000 live births in 2017. Bangladesh was found in second position and Nepal was in third position for lowest under-five child mortality rate in 2017 among South Asian countries [23]. From the result of this study it was found that under-five child mortality rate was associated with mother's education, birth order, size of babies at birth, taking ANC. Although under-five child mortality rate for living area was found statistically insignificant in this study, child mortality rate was found higher among rural area living child contrast to urban living 
child. From the report of several countries it was found that child mortality rate was also high in rural area $[12,17,24,25]$. Children living in rural area did not get proper health care facilities contrast to urban area and rural living parents didn't have proper knowledge about child and maternal health, which would be the main reasons for high rate of child mortality in rural area. Among all the divisions, mortality rate was found significantly higher in Sylhet compared to others $(p=0.05)$. Cultural activities, religious influence, superstitions may be responsible for the high rate of death in Sylhet. This division was lagging behind because of insufficient health care provider of maternal and child health, antenatal care service and vaccination program among mother and children [26]. According to the report of another study from BDHS data 2014, it was found that under-five child mortality rate was also high in Sylhet division [15].

Under-five child mortality was found higher for $4^{\text {th }}$ birth order compared to $1 \mathrm{st}$ birth order which was similar with previous study $[15,16]$. But contrast result was also found for different studies [27]. Our findings show that under-five child mortality rate was found higher among the children who were very small size at their birth compared to very large size. Same results were found for several studies [28, 29]. Premature birth, low nutritional status of mother may be the reason for small size of birth which is significantly associated with under-five child mortality [28, 29]. A significant association of under-five child mortality and mother's educational level was found in this study. A reduction of mortality was found among the child's mother with secondary or higher education compared to no education. Which indicates that improving maternal education will reduce child mortality rate. It is expected that educated mother are more likely to understand better health issues for themselves and their children. Educated mother can also play an important role against social and religious superstitions as well as different family crisis [30, 31,32]. Although wealth index of children's family was not statistically significant in our study, it may had a great impact on child mortality. Poor family had a higher risk for child mortality compared to rich and middle income family due to proper nutation and living standard [33]. Under-five mortality was higher among the children whose mother did not take any antenatal care during their pregnancy, which was statistically significant at $10 \%$ level of significance. Although place of delivery was not significant in our study, it may have a great influence in child mortality [34]. Our report showed an insignificant result for the source of pure drinking water and type of improved sanitation as an influential effect for child mortality, which was inconsistent with other study result. According to the result of several studies, it was found that pure drinking water and sanitation have influence on child mortality $[25,35,36,37]$.

Improvement of sanitation and pure drinking water predict a large reduction in diarrhea, cholera and other infectious disease which are responsible for child mortality [37]. In developing countries, household coverage with water and sanitation could lead to a total reduction of 2.2 million child deaths per year [35].

Under-five child mortality is one of the major public health problem in Bangladesh and this study give fundamental fact to understand child mortality. Government and other non-government institution and NGO's should play a vital role by implementing different family planning program among the women to reduce under-five child mortality and also by implementing different policies and strategies to improve maternal education. 


\section{Strengths and limitation}

The main strengths of this study were that it had been based on most recently nationally representative population data with children, their household and communities in which they reside. Since it was a nationally representative data, a large sample was used in this study. So, it was easily possible to generalize results of child mortality in Bangladesh aged below 5 years.

In this study, cross-sectional data had been used which restricted any conclusions about the causal effect of the factors. Socioeconomic condition of the household could be different at the time of survey and at the time of child death, which might lead a bias result in this analysis. Some important variables were founding insignificant due to a large number of missing values and non-response in data set. Furthermore, some important variables such as mothers working status, mothers BMI, child nutritional status as well as on diarrhea, cholera, fever were not included in this study due to data unavailability.

\section{Conclusion}

Though under-five child mortality rate has been reducing by a remarkable rate for last few years in Bangladesh, the rate is still high to reach the expected level according to Sustainable Development Goals (SDGs). This study finding for the risk factors associated with under-five child mortality are very important for the identification of new policies and interventions as well as existing policies and interventions to reduce the rate of mortality in expected level. Increasing mother's education level may reduce the mortality rate. Taking ANC during pregnancy may also reduce child mortality. Some important factors which are responsible for child mortality such as maternal nutritional status, child nutritional status, cultural condition, environmental condition were not included in this study due to data unavailability. Further investigations should be constructed considering these imperceptibly factors that are probably going to be related with under-five child mortality to more readily comprehend the relationship among family and community level elements and child mortality in Bangladesh. A proper guideline and new policies as well as interventions should be introduced focusing on those characteristics by government and non-government institutions to reduce the rate of under-five child mortality in Bangladesh.

\section{Abbreviations}

MICS: Multiple Indicator Cluster Survey; WHO: World Health Organization; NGO: Non-Government Organization; ANC: Antenatal Care

\section{Declarations}

\section{Ethics approval and consent to participate}


The study was approved by the by technical committee of the Government of Bangladesh lead by Bangladesh Bureau of Statistics (BBS). Written informed consent was obtained from the participants.

\section{Consent for publication}

Not applicable

\section{Availability of data and materials}

Data set used in this study is available at https://mics.unicef.org/surveys.

\section{Competing interests}

Authors have no conflict of interest.

\section{Funding}

This research has no fund.

\section{Authors' contribution}

$\mathrm{MMI}$ and FMN developed the study concepts and analyzed the data. MMI, FMN, MRH, and MAU drafted the manuscript. All authors read, critically reviewed, and approved the final version of the paper.

\section{Acknowledgements}

We would like to thank Bangladesh Bureau of Statistics (BBS) and Multiple Indicator Cluster Survey (MICS) 2019, Bangladesh for providing us nationally representative base data.

\section{References}

1. J. W. McGuire, "Basic health care provision and under-5 mortality: a cross-national study of developing countries," World Development, vol. 34, no. 3, pp. 405-425, 2006.

2. World Health Organization, Report, Global health observatory (GHO) data, 2018, http://www.who.int/gho/child health/health/mortality/mortality under five text/en/.

3. Children: reducing mortality - World Health Organization. www.who.int > Newsroom > Fact sheets > Detail.

4. WHO| sustainable-development-goals/targets/en. https://www.who.int/topics. 
5. Bangladesh Child mortality rate, 1960-2018 - knoema.com. knoema.com > World Data Atlas Bangladesh > Health.

6. NIPORT Mitra and Associates and ICF. Bangladesh demographic and health survey 2014 (policy brief). Technical report, National Institute of Population Research and Training (NIPORT), Mitra and Associates, and ICF International. 2016.

7. NIPORT MitraandAssociates and ICF. Bangladesh demographic and health survey 2014 (policy brief). Technical report, National Institute of Population Research and Training (NIPORT), Mitra and Associates, and ICF International. 2016.

8. Doctor HV. The effect of living standards on childhood mortality in Malawi. 2004.

9. Quamrul HC, Rafiqul I, Kamal H. Socio-economic determinants of neonatal, post neonatal, infant and child mortality. Int J Sociol Anthropol 2010;2:118-25.

10. Mathews T, MacDorman MF. Statistics NCFH: infant mortality statistics from the 2004 period linked birth, infant death data set. US Department of Health \& Human Services, Centers for Disease Control and Prevention, National Center for Health Statistics, 2007.

11. Grepin K, Bharadwaj P. Maternal education and child mortality in zimbabwe. J Health Econ. 2015;44(6):97-117.

12. Aheto JM. Predictive model and determinants of under-five child mortality: evidence from the 2014 Ghana demographic and health survey. BMC public health. 2019 Dec 1;19(1):64.

13. Bairagi R, Sutradhar S, Alam N. Levels, trends and determinants of child mortality in matlab, bangladesh 1966-1994. Asia-Pac Popul J. 1999;14(2): 51-68.

14. Kabir A, Islam M, Ahmed M, Barbhuiya K. Factors influencing infant and child mortality in bangladesh. Sciences. 2001;1(5):292-5.

15. Khan JR, Awan N. A comprehensive analysis on child mortality and its determinants in Bangladesh using frailty models. Archives of Public Health. 2017 Dec 1;75(1):58.

16. Abir T, Agho KE, Page AN, Milton AH, Dibley MJ. Risk factors for under-5 mortality: evidence from Bangladesh Demographic and Health Survey, 2004-2011. BMJ open. 2015 Aug 1;5(8):e006722.

17. Gebretsadik S, Gabreyohannes E. Determinants of under-five mortality in high mortality regions of Ethiopia: an analysis of the 2011 Ethiopia Demographic and Health Survey data. International Journal of Population Research. 2016;2016.

18. Rahman MS, Rahman MS, Rahman MA. Determinants of death among under-5 children in Bangladesh. Journal of Research and Opinion. 2019 Mar 30;6(3):2294-302.

19. Pathey P. Bangladesh multiple indicator cluster survey 2019. Bangladesh Bur. Stat. UNICEF Bangladesh. 2020:2020. https://mics.unicef.org/surveys.

20. Kaplan, E. L. and P. Meir. 1958. Nonparametric Estimation from Incomplete Observations. Journal of the American Statistical Association 53(282): 457-481.

21. Cox, D.R. 1972. Regression Models and Life-Tables. Journal of the Royal Statistical Society. Series $B$ 34(2):187-220. 
22. Survival analysis | The BMJ. www.bmj.com > publications > statistics-square-one > 12.

23. India's Under-5 Mortality Now Matches Global Average, But Bangladesh, Nepal Do Better. www.indiaspend.com > indias-under-5-mortality-now.

24. Fikru C, Getnet M, Shaweno T. Proximate Determinants of Under-Five Mortality in Ethiopia: Using 2016 Nationwide Survey Data. Pediatric Health, Medicine and Therapeutics. 2019;10:169.

25. Kaldewei C. Determinants of Infant and Under-Five Mortality-The Case of Jordan. Technical note, February. 2010.

26. Nath SR. Exploring the marginalized: a study in some selected upazilas of Sylhet division in Bangladesh. Dhaka: BRAC; 2013. http://research.brac.net/ new/rednews/exploring-the-marginalizeda-study-in-some-selectedupazilas-of-sylhet-division-in-bangladesh. Accessed 30 Jan 2017.

27. Chandrasekhar S. Infant Mortality, Population Growth and Family Planning in India. United Kingdom: Routledge; 2010.

28. Alexander GR, Kogan M, Bader D, Carlo W, Allen M, Mor J. Us birth weight/gestational age-specific neonatal mortality: 1995-1997 rates for whites, hispanics, and blacks. Pediatrics. 2003;111(1):61-6.

29. Lau C, Ambalavanan N, Chakraborty H, Wingate MS, Carlo WA. Extremely low birth weight and infant mortality rates in the united states. Pediatrics. 2013;131(5):855-60.

30. Aheto JMK, Taylor BM, Keegan TJ, Diggle PJ. Modelling and forecasting spatio-temporal variation in the risk of chronic malnutrition among underfive children in Ghana. Spat Spatiotemporal Epidemiol. 2017;21:37-46.

31. Buor D. Mothers' education and childhood mortality in Ghana. Health Policy. 2003;64(3):297-309.

32. Adekanmbi VT, Kayode GA, Uthman OA. Individual and contextual factors associated with childhood stunting in Nigeria: a multilevel analysis. Matern Child Nutr. 2013;9(2):244-59.

33. Azuike EC, Onyemachi PE, Amah CC, Okafor KC, Anene JO. Determinants of Under-Five Mortality in South-Eastern Nigeria. J Community Med Public Health Care. 2019;6:049.

34. Pal S. Impact of hospital delivery on child mortality: an analysis of adolescent mothers in Bangladesh. Social Science \& Medicine. 2015 Oct 1;143:194-203.

35. Günther I, Fink G. Water and sanitation to reduce child mortality: The impact and cost of water and sanitation infrastructure. The World Bank; 2011 Mar 1.

36. Ezeh OK, Agho KE, Dibley MJ, Hall J, Page AN. The impact of water and sanitation on childhood mortality in Nigeria: evidence from demographic and health surveys, 2003-2013. International journal of environmental research and public health. 2014 Sep;11(9):9256-72.

37. Headey D, Palloni G. Water, sanitation, and child health: evidence from subnational panel data in 59 countries. Demography. 2019 Apr 15;56(2):729-52.

\section{Figures}


Bangladesh Multiple Indicator Cluster Survey (MICS), conducted in 2019 by the Bangladesh Bureau of Statistics (BBS)

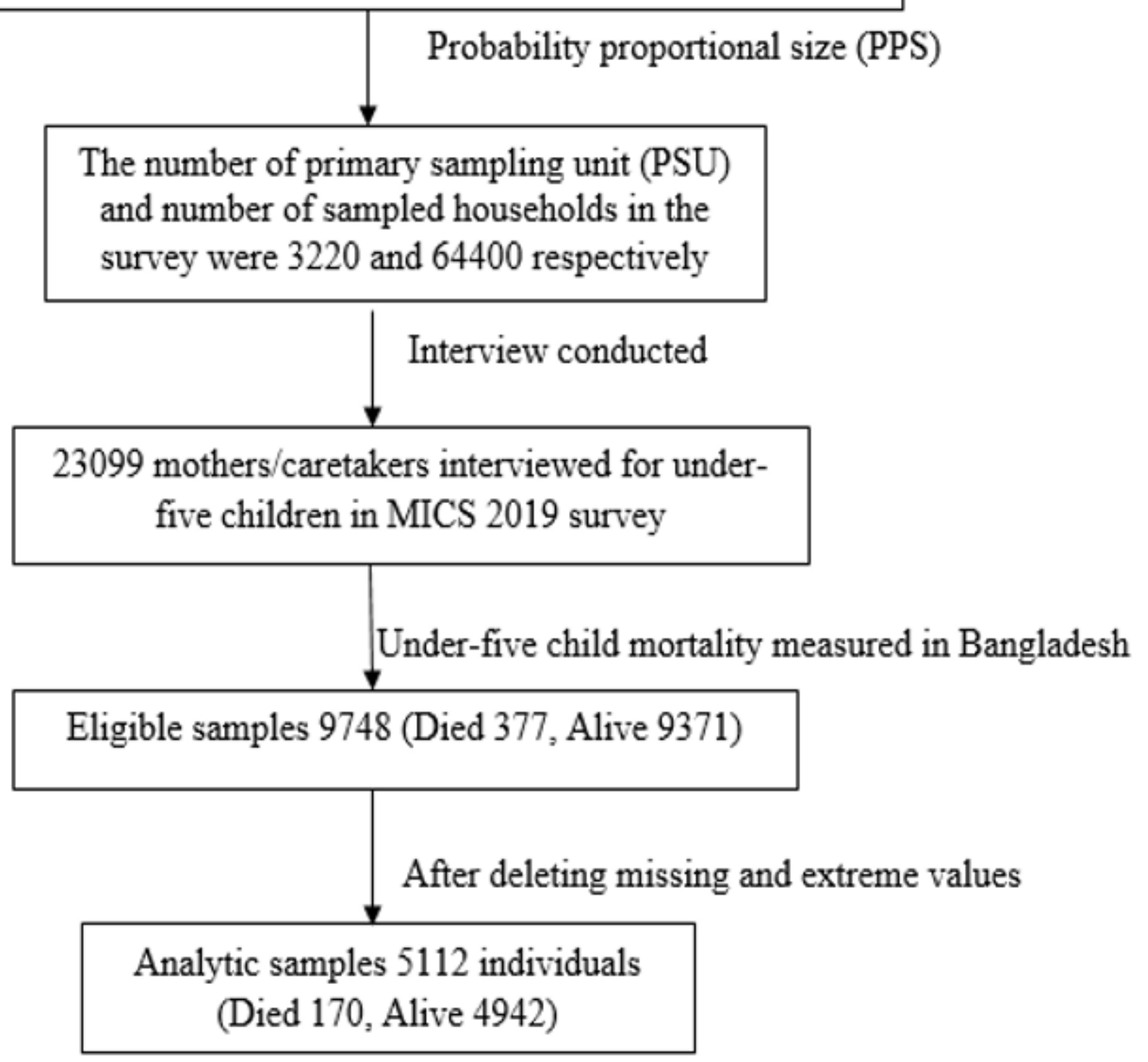

Figure 1

Flowchart of the analytic sample selection process. 

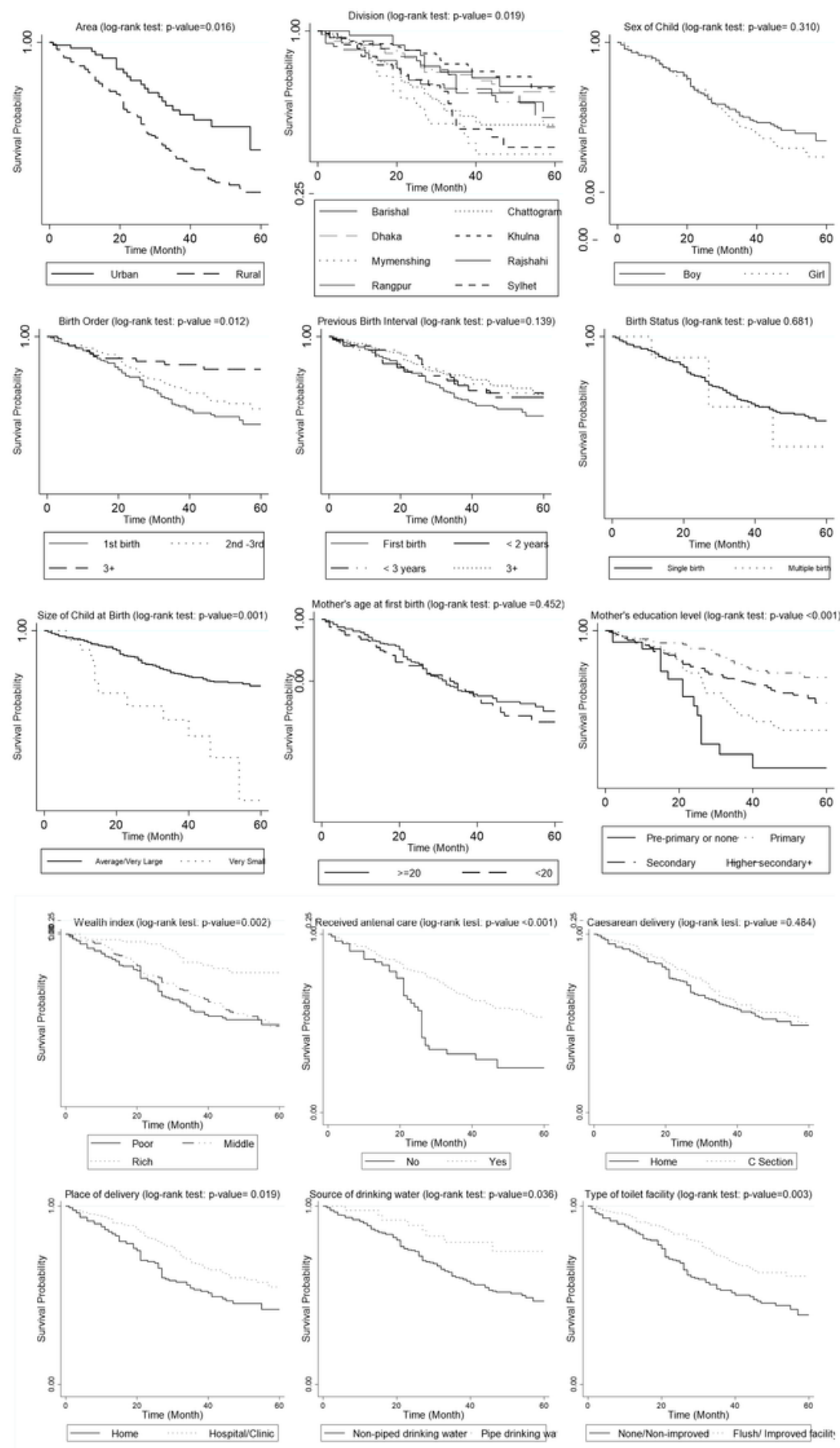

Figure 2

Survival curves for the selected variables obtained from P-L method along with log-rank test p-values. 